\title{
Analysis and Design of Cavity-Backed Probe-Fed Hybrid Microstrip Antennas on FR4 Substrate
}

\author{
D. C. Nascimento, Prêntice C. Ribeiro Filho, Alexis F. Tinoco-S, and J. C. da S. Lacava
}

Instituto Tecnológico de Aeronáutica, Laboratório de Antenas e Propagação, Praça Marechal Eduardo Gomes 50, 12228-900 São José dos Campos, SP, Brazil

Correspondence should be addressed to D. C. Nascimento; danielcn@ita.br

Received 26 August 2015; Accepted 17 September 2015

Academic Editor: N. Nasimuddin

Copyright (C) 2015 D. C. Nascimento et al. This is an open access article distributed under the Creative Commons Attribution License, which permits unrestricted use, distribution, and reproduction in any medium, provided the original work is properly cited.

\begin{abstract}
A novel cavity-backed probe-fed linearly polarized microstrip antenna based on the concept of hybrid radiators is proposed and implemented. The resulting flush-mounted antenna exhibits symmetrical bandwidth, low cross-polarization radiation in the $H$ plane, due to its hybrid patch, and low cost, since it can be built on a FR4 laminate. Substrate integrated waveguide technology is used in the fabrication of the metallic cavity. The effect of mutual coupling is analyzed for two classical arrangements: the side-byside and the collinear configurations.
\end{abstract}

\section{Introduction}

Conventional microstrip antennas, made up of a metallic patch printed on top of a grounded dielectric layer, exhibit unique characteristics such as small volume and compatibility with integrated circuits at microwave frequencies, having thus become customary components in a variety of applications [1]. In order to achieve higher levels of radiation efficiency, microstrip antennas have been designed on expensive low-loss tangent (about 0.002) laminates [2-4]. On the other hand, now that both market and technology are ready for mass production, techniques for designing microstrip antennas on low-cost but electrically poorer FR4 substrate have been reported [5-14].

Nonetheless, the use of the FR4 substrate introduces additional complexity to the antenna design [15-17], due not only to the inaccuracy of its relative permittivity value but mainly to its considerable loss tangent (around 0.02). Variations in FR4 permittivity can shift the nominal operating frequency, whereas the large loss tangent affects the antenna bandwidth and gain resulting in poor radiation efficiency-as low as $30 \%$ (at $1.6 \mathrm{GHz}$ ) for a $1.5 \mathrm{~mm}$ thick substrate. To improve this relevant parameter, antennas have been manufactured on moderately thick substrates-thus achieving $70 \%$ radiation efficiency with a $6.0 \mathrm{~mm}$ thick substrate (at $2 \mathrm{GHz}$ ) [17].
However, microstrip antennas on thick substrates can exhibit a significant level of cross-polarization in their $H$-planes [1820] and guided-wave effects-the latter substantially affecting their radiation efficiency [21]. To overcome these limitations, a new effective topology was recently proposed-a hybrid microstrip patch backed by a metallic cavity $[22,23]$. The hybrid radiator is meant to reduce the cross-pol level in the aforementioned plane $[23,24]$ whereas the cavity backing can suppress the guided-wave effects [25]. Moreover, fed by coaxial probe, conventional and hybrid microstrip antennas on thick substrates, designed according to the traditional procedure [26], can exhibit highly inductive input impedance.

Techniques to compensate for the probe's inductive reactance are available [27-34], though at the cost of greater complexity in the antenna design and manufacture. To handle this drawback, an efficient technique for designing probe-fed, moderately thick microstrip antennas has been proposed, permitting the accurate design of linearly polarized microstrip antennas based only on their intrinsic characteristics, without any external matching network [35-40].

In this paper, low-cost cavity-backed hybrid microstrip antenna is designed at $2.45 \mathrm{GHz}$ for ISM band $(2.4-2.5 \mathrm{GHz})$ operation, according to the zero input reactance condition [17], resulting in symmetrical bandwidth (with respect to the operating frequency) and real input impedance (at that 


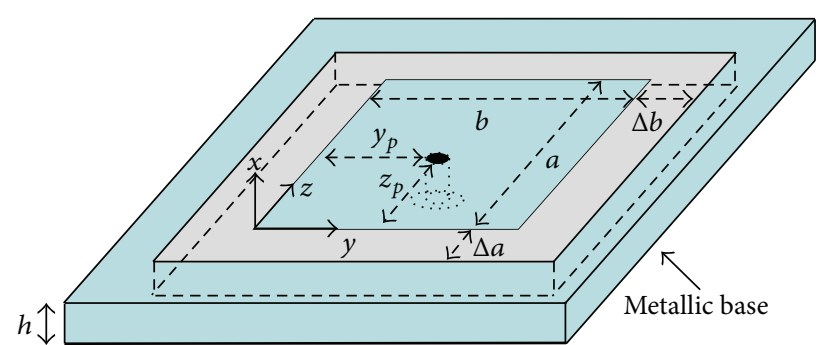

FIgURE 1: Cavity-backed rectangular-patch microstrip antenna.

frequency). Nowadays, the design can be carried out using commercial software like Ansoft Designer [41] and HFSS [42]. However, as their focus is on analysis, the development process becomes more effective when a predesign (PD) of the geometry under study is first obtained before optimization in the software environment. Analytical methods such as the classical cavity model [43] have been used for this purpose [23]. Unfortunately, as the classical model calculates the radiated field directly from the fundamental resonant mode $\mathrm{TM}_{11}$, it cannot properly explain the asymmetry in the $E$ plane radiation pattern of probe-fed moderately thick hybrid antennas [23]. To take this effect into account, the radiated fields are computed from $\mathrm{TM}_{11}, \mathrm{TM}_{10}$, and $\mathrm{TM}_{12}$ modes.

This paper is organized as follows. After the antenna predesign carried out in Section 2, the following section is dedicated to its optimization, now under the zero input reactance condition $\left(X_{\text {in }}=0\right)$ [17]. Since the manufacture of lateral electric walls in microstrip structures is not a simple task, substrate integrated waveguide (SIW) technology [44] is used in the fabrication of the metallic cavity. The design of this new topology is presented in Section 4 whereas the mutual coupling in both side-by-side and collinear arrays is analyzed in Section 5. A prototype is shown in Section 6-along with experimental results validating the proposed geometry. Final comments are presented in Section 7.

\section{Predesign Procedure}

Low profile, as well known, is an important characteristic of microstrip antennas. However, in flush-mounted applications, radiators are, in general, embedded in cavities. Cavity-backed patch antennas have many attractive features such as the reduction of guided-wave effects, enhanced mechanical and thermal performance, and, in particular, the improved isolation of the radiating element from the rest of the system [25, 40, 45-48]. The typical geometry of a conventional cavity-backed rectangular-patch antenna is shown in Figure 1 , where $\left(y_{p}, z_{p}\right)$ denotes the probe position, $a$ and $b$ denote the patch sides, $\Delta a$ and $\Delta b$ denote the slots around the patch, and $h$ denotes the substrate thickness. The patch is centered on the cavity and printed on top of a dielectric layer with the same dimensions as the cavity $(h \times(a+2 \Delta a) \times(b+2 \Delta b))$, with $\Delta a$ and $\Delta b$ larger than $h$, in order not to disturb the fringing fields. Moreover, the patch is directly fed by a $50-\Omega$ SMA connector.

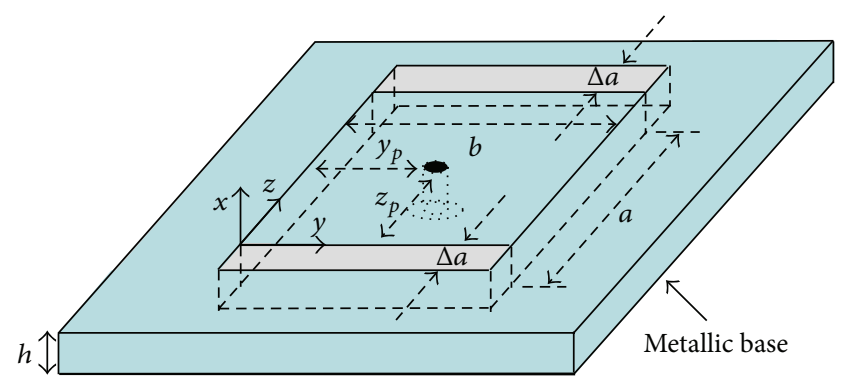

FIGURE 2: Cavity-backed probe-fed hybrid microstrip antenna.

Such flush-mounted radiator exhibits significant crosspolarization level in the $H$-plane (CPLH-P), similar to the conventional probe-fed rectangular-patch antenna [49], but this drawback can nonetheless be overcome in a simple way with a hybrid rectangular patch operating in $\mathrm{TM}_{11}$ mode. In this case, two opposite sides of the patch are connected directly to the ground [22-24, 50]. An original implementation-by embedding in a metallic cavity-is depicted in Figure 2. In this new geometry, named cavitybacked hybrid microstrip (CBHM) antenna, the slots of dimension $\Delta b$ were eliminated without significantly affecting the antenna characteristics [23] and the dielectric layer is now a parallelepiped with dimensions $b \times(a+2 \Delta a) \times h$, and $\Delta a>h$.

Though originally developed for electrically thin conventional microstrip antennas, the cavity (CV) model is used in this paper for estimating the electric characteristics of moderately thick cavity-backed hybrid radiators. Considering the antenna shown in Figure 2 excited by a vertical strip of uniform current density $I_{0}$ located at $\left(y_{p}, z_{p}\right)$, the electric field inside the cavity is given by $[23,50]$

$$
E_{x}(y, z)=\sum_{m} \sum_{n} E_{m n} \sin \left(\frac{m \pi y}{b}\right) \cos \left(\frac{n \pi z}{a}\right),
$$

where

$$
\begin{aligned}
& E_{m n}=\frac{2 i \omega \mu_{0} I_{0}}{a b} \frac{\xi_{n}}{\left(k_{\mathrm{eff}_{m n}}^{2}-k_{m n}^{2}\right)} \sin \left(\frac{m \pi y_{p}}{b}\right) \\
& \cdot \cos \left(\frac{n \pi z_{p}}{a}\right) \operatorname{sinc}\left[\frac{m \pi \ell_{p}}{2 b}\right], \\
& k_{\mathrm{eff}_{m n}}^{2}=k_{0}^{2} \varepsilon_{r}\left(1-i \delta_{\mathrm{eff}_{m n}}\right), \\
& k_{m n}^{2}=\left(\frac{m \pi}{b}\right)^{2}+\left(\frac{n \pi}{a}\right)^{2},
\end{aligned}
$$

$\xi_{n}=1$ if $n=0$ or $\xi_{n}=2$ if $n \neq 0, k_{0}$ and $\mu_{0}$ are the free-space wave number and permeability, respectively, $\varepsilon_{r}$ is the relative permittivity of the substrate, $\ell_{p}$ is the effective width of the strip, $\delta_{\text {eff }_{m n}}$ is the effective loss tangent of $(m, n)$ mode [43], $\operatorname{sinc} x=(\sin x) / x$, and $m \neq 0$. 
Consequently, the input impedance of electric moderately thick CBHM antennas can be calculated by

$$
\begin{aligned}
Z_{\text {in }}= & \frac{i 2 \omega \mu_{0} h}{a b} \sum_{m} \sum_{n} \frac{\xi_{n}}{k_{m n}^{2}-k_{\mathrm{eff}_{m n}^{2}}^{2}} \sin ^{2}\left(\frac{m \pi y_{p}}{b}\right) \\
& \cdot \cos ^{2}\left(\frac{n \pi z_{p}}{a}\right) \operatorname{sinc}^{2}\left[\frac{m \pi \ell_{p}}{2 b}\right] .
\end{aligned}
$$

On the other hand, as the far fields are determined from magnetic currents positioned along the radiating edges, the following expression is obtained:

$$
\vec{E}=\frac{k_{0}^{2} \eta_{0} I_{0} h}{a} \frac{e^{-i k_{0} r}}{r} g(\theta, \phi)[\cos \phi \hat{\theta}-\sin \phi \cos \theta \widehat{\phi}],
$$

where

$$
\begin{aligned}
& g(\theta, \phi) \\
& =\sum_{m} \sum_{n} \frac{m \xi_{n}}{k_{\mathrm{eff}_{m n}}^{2}-k_{m n}^{2}}\left\{\frac{\cos (m \pi) e^{i k_{0} b \sin \theta \sin \phi}-1}{\left(k_{0} b \sin \theta \sin \phi\right)^{2}-(m \pi)^{2}}\right\} \\
& \cdot\left\{\cos (n \pi) e^{i k_{0} a \cos \theta}-1\right\} \sin \left(\frac{m \pi y_{p}}{b}\right) \cos \left(\frac{n \pi z_{p}}{a}\right) \\
& \cdot \operatorname{sinc}\left[\frac{m \pi \ell_{p}}{2 b}\right] .
\end{aligned}
$$

However, as the resonance frequency of $\mathrm{TM}_{11}$ mode depends on $a$ and $b$, antennas of different dimensions can be designed to operate at the same frequency. Therefore, an appropriate criterion is required for choosing the patch dimensions and the feeder position $\left(y_{p}, z_{p}\right)$ so the antenna can work properly.

The modes closer to the fundamental one, as mentioned in [23], are $\mathrm{TM}_{10}, \mathrm{TM}_{20}, \mathrm{TM}_{21}$, and $\mathrm{TM}_{12}$. Thus, the predesign criterion consists of controlling these adjacent modes so they do not disturb the antenna operation in the convenient $\mathrm{TM}_{11}$ fundamental mode. A simple way to suppress $\mathrm{TM}_{20}$ and $\mathrm{TM}_{21}$ modes is to feed the patch at $y_{p}=b / 2$, where their electric fields are minimum. Accordingly, the general expressions (3) and (4) can be rewritten as

$$
\begin{aligned}
Z_{\mathrm{in}_{11}} & =\frac{i \omega \alpha_{11}}{k_{11}^{2}-k_{\mathrm{eff}_{11}}^{2}}+i \omega \sum_{\substack{m \\
m \neq 1}} \sum_{\substack{n \\
n \neq 1}} \frac{\alpha_{m n}}{k_{m n}^{2}-k_{0}^{2} \varepsilon_{r}}, \\
\vec{E}_{11} & =A_{0} f(\theta, \phi) \\
\cdot & \sum_{n=0}^{2}\left\{\frac{\xi_{n} \cos \left(n \pi z_{p} / a\right)}{k_{\mathrm{eff}_{1 n}}^{2}-k_{1 n}^{2}}\left[\cos (n \pi) e^{i k_{0} a \cos \theta}-1\right]\right\} \\
\cdot & {[\sin \phi \cos \theta \hat{\phi}-\cos \phi \hat{\theta}], }
\end{aligned}
$$

TABLE 1: CV and CBHM antennas dimensions.

\begin{tabular}{lccc}
\hline & $\mathrm{CV}\left(\ell_{p}=1.3 \mathrm{~mm}\right)$ & CBHM-PD & CBHM-HFSS \\
\hline$a[\mathrm{~mm}]$ & 37.21 & 31.28 & 31.98 \\
$b[\mathrm{~mm}]$ & 50.00 & 50.00 & 50.00 \\
$z_{p}[\mathrm{~mm}]$ & 14.06 & 11.10 & 12.53 \\
\hline
\end{tabular}

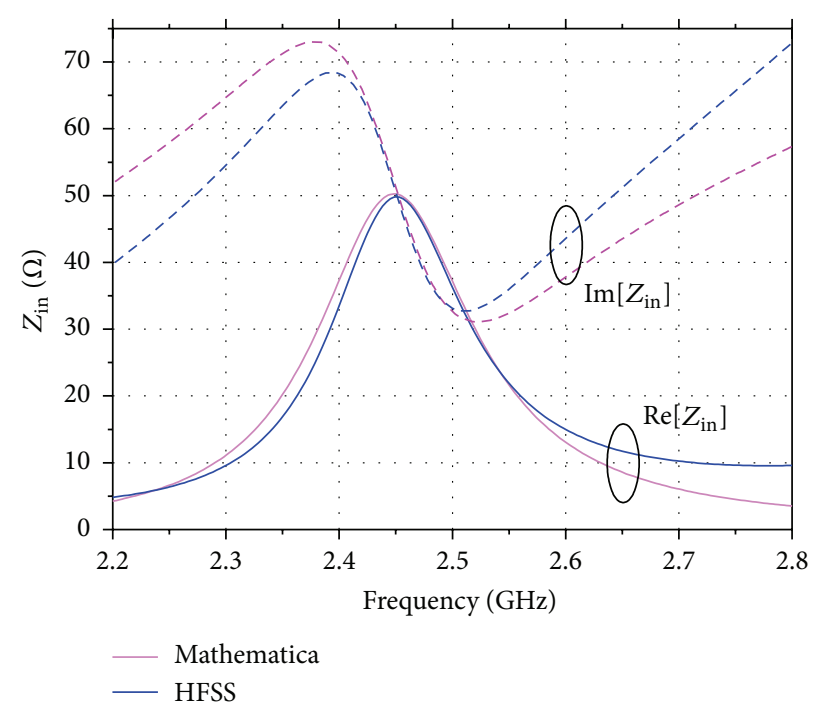

FIGURE 3: Input impedance of CBHM antennas.

where

$$
\begin{aligned}
& \alpha_{m n}=\frac{2 \mu_{0} h \xi_{n}}{a b} \sin ^{2}\left(\frac{m \pi y_{p}}{b}\right) \cos ^{2}\left(\frac{n \pi z_{p}}{a}\right) \\
& \cdot \operatorname{sinc}^{2}\left[\frac{m \pi \ell_{p}}{2 b}\right], \\
& A_{0}=\frac{k_{0}^{2} \eta_{0} I_{0} h}{a} \frac{e^{-i k_{0} r}}{r} \sin \left(\frac{\pi y_{p}}{b}\right) \operatorname{sinc}\left[\frac{\pi \ell_{p}}{2 b}\right], \\
& f(\theta, \phi)=\frac{e^{i k_{0} b \sin \theta \sin \phi}+1}{\left(k_{0} b \sin \theta \sin \phi\right)^{2}-\pi^{2}} .
\end{aligned}
$$

Based on the CV model, Mathematica [51] notebook was implemented for design purposes. With that, a CBHM antenna on a $6.6 \mathrm{~mm}$ moderately thick (for good radiation efficiency [17]) FR4 material $\left(\varepsilon_{r}=4.2, \delta=0.02\right)$, fed by a $50-\Omega$ SMA coaxial connector of $0.65 \mathrm{~mm}$ radius, was designed to operate at $2.45 \mathrm{GHz}$, according to the traditional procedure [26]. Table 1 shows the CV and the CBHM predesign dimensions-the latter obtained from the CV ones using Hammerstad [52]. Graphics of input impedance and radiation patters are presented in Figures 3 and 4. For validation purpose, a CBHM antenna was designed in HFSS starting from the predesign results, with $\Delta a=14 \mathrm{~mm}$. Their dimensions are also shown in Table 1 and the simulations are superimposed on the respective figures. The input impedance was calculated considering the antenna embedded in a $140 \mathrm{~mm}$ square metallic plate and the radiation patterns under the infinite ground plane condition. As seen from 


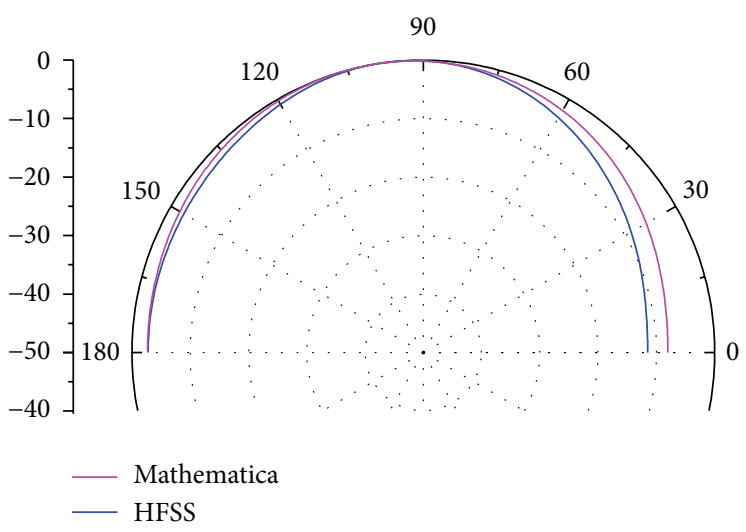

(a) E-plane

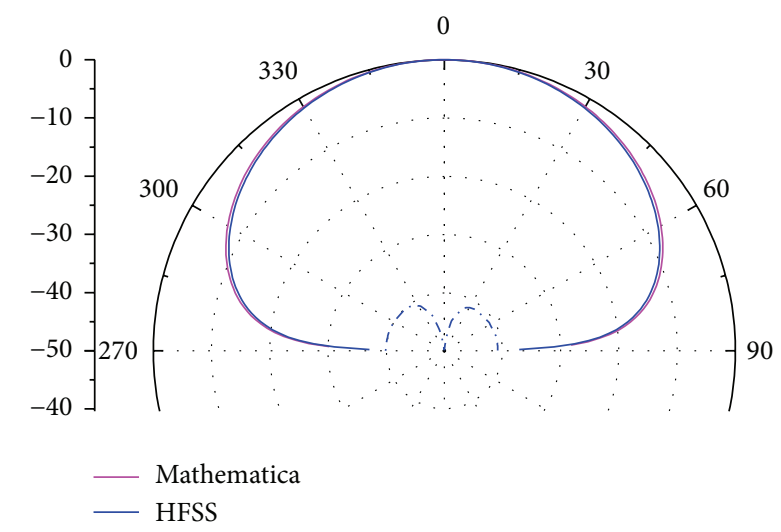

(b) $H$-plane

FIGURE 4: Radiation patterns of CBHM antennas.

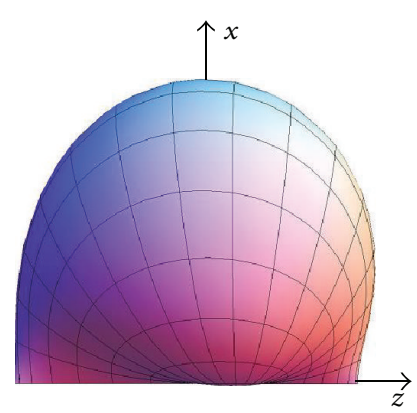

(a) Co-pol

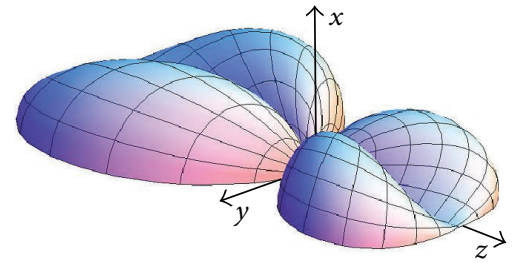

(b) Cross-pol

FIGURE 5: Co-pol and cross-pol 3D radiation patterns.

TABLE 2: Electric characteristics of CBHM antennas.

\begin{tabular}{lcc}
\hline & CBHM-PD & CBHM-HFSS \\
\hline$Z_{\text {in }}[\Omega]$ & $50.24+i 51.34$ & $49.81+i 50.53$ \\
Directivity [dB] & 6.7 & 7.1 \\
Radiation efficiency [\%] & 70.7 & 67.3 \\
\hline
\end{tabular}

Figure 4(a), differently from the simple CV model that utilizes only the fundamental mode [23], the radiation pattern computed from $\mathrm{TM}_{11}, \mathrm{TM}_{10}$, and $\mathrm{TM}_{12}$ modes exhibits the well known $E$-plane ( $x z$ plane) asymmetry $[22,23]$.

Table 2 presents comparisons between the electric characteristics of the antennas simulated in Mathematica and HFSS. The input impedance, directivity, and radiation efficiency were calculated at the operating frequency. Good agreement between HFSS and Mathematica results is observed.

According to the coordinate system shown in Figure 2, $E_{\theta}$ component describes the copolarized radiation whereas the cross-pol one is given by $E_{\phi}$. As seen from Figure 4(b), the antenna cross-pol in the $H$-plane is very low, as expected. In order to illustrate the radiation behavior, typical 3D patterns calculated at $2.45 \mathrm{GHz}$, using the Mathematica notebook, are shown in Figure 5. As noted, the deep valley seen along the $x y$ plane causes the low cross-pol radiation in the $H$-plane, as illustrated in Figure 5(b).
In conclusion, through this simple analytic model, the electric characteristics of CBHM antennas can be estimated in order to quickly establish their predesign dimensions. In the present case, however, the antenna is not properly matched to the 50- $\Omega$ SMA connector, since the traditional design procedure was applied. The following section is dedicated to its optimization.

\section{Antenna Optimization}

The optimization procedure starts from the predesign dimensions established in the previous section, but now considering the antenna embedded in a $100 \mathrm{~mm}$ square metallic plate. Following the zero input reactance condition [17], the predesign geometry is input into HFSS with the feed probe positioned near the radiating edge (i.e., $z_{p} \cong 0 \mathrm{~mm}$ ), so as to check whether capacitive input impedances occur at frequencies above the operating one. If so, the antenna can then be perfectly matched to the $50-\Omega$ SMA connector at a certain intermediate feed probe position. To carry this out, the probe position $z_{p}$ is then gradually displaced from the edge until the desired impedance is reached. The frequency where this happens must now be shifted down to the desired operating frequency through the rescaling of the antenna geometry by increasing the patch dimensions ( $a$ and $b$ ). Hence, the following optimized dimensions were obtained: $a=32.90 \mathrm{~mm}$, $b=51.40 \mathrm{~mm}, y_{p}=b / 2$, and $z_{p}=10.85 \mathrm{~mm}$, with $\Delta a=10 \mathrm{~mm}$ 


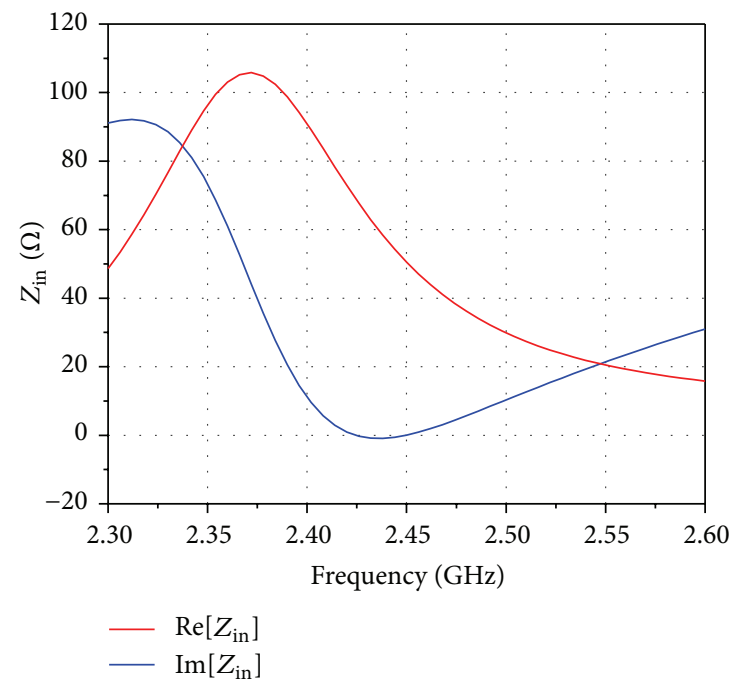

FIGURE 6: Input impedance of the CBHM antenna.

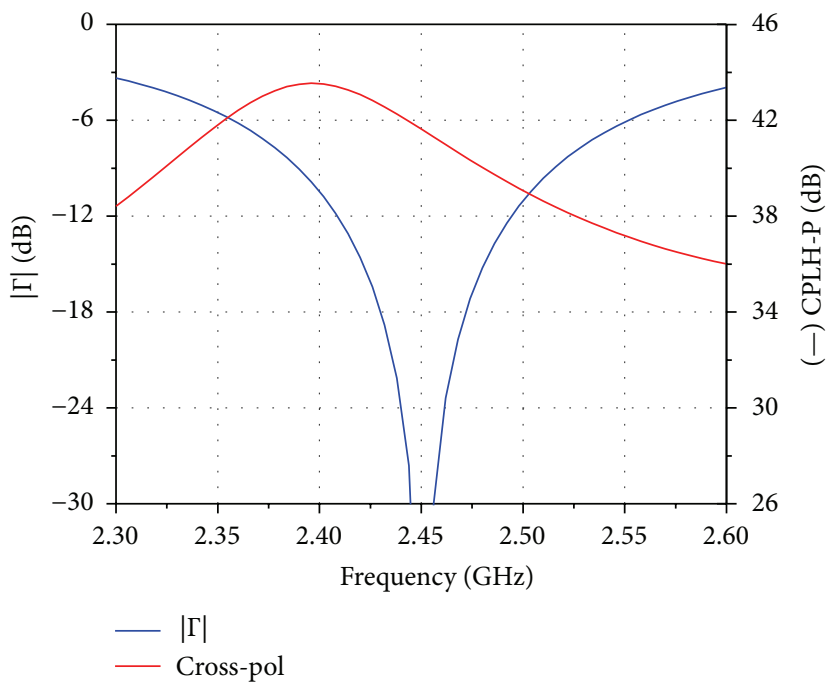

Figure 7: Reflection coefficient magnitude and CPLH-P of the CBHM antenna.

$\cong 1.5 \mathrm{~h}$. The resulting input impedance, reflection coefficient magnitude, and CPLH-P are presented in Figures 6 and 7.

As seen, after optimization, the antenna matches perfectly the $50-\Omega$ SMA connector and presents a $4.5 \%$ symmetrical bandwidth $(110 \mathrm{MHz})$ for $10-\mathrm{dB}$ return loss with respect to the operating frequency, covering the entire ISM band. Additionally, the radiator exhibits $69.2 \%$ radiation efficiency and 7.4- $\mathrm{dB}$ directivity at $2.45 \mathrm{GHz}$.

To complete the analysis, the co-pol and the cross-pol radiation patterns, simulated at $2.45 \mathrm{GHz}$ and plotted in the $E$ - and $H$-planes, are presented in Figure 8. As expected, the cross-pol radiation in the $H$-plane ( $x y$ plane) is low. As noted, the CPLH-P is around $-41.6 \mathrm{~dB}$ at the operating frequency and under $-39 \mathrm{~dB}$ all over the operating band, as shown in Figure 7.

Once more, to illustrate the cross-pol behavior, typical $3 \mathrm{D}$ radiation patterns of $\mathrm{CBHM}$ and conventional probe-fed rectangular-patch antennas, plotted at $2.45 \mathrm{GHz}$, are shown in Figure 9.
TABLE 3: SIW antenna dimensions.

\begin{tabular}{lcccc}
\hline & $A-1$ & $A-2$ & $A-3$ & $A-4$ \\
\hline$a[\mathrm{~mm}]$ & 32.6 & 32.25 & 32.25 & 31.7 \\
$b[\mathrm{~mm}]$ & 50.9 & 50.4 & 50.4 & 49.5 \\
$z_{p}[\mathrm{~mm}]$ & 10.6 & 10.5 & 10.5 & 10.35 \\
$\Delta c_{y}[\mathrm{~mm}]$ & 6 & 12 & 24 & 24 \\
$\Delta c_{z}[\mathrm{~mm}]$ & 6 & 12 & 12 & 16 \\
Number of pins & 40 & 20 & 16 & 14 \\
\hline
\end{tabular}

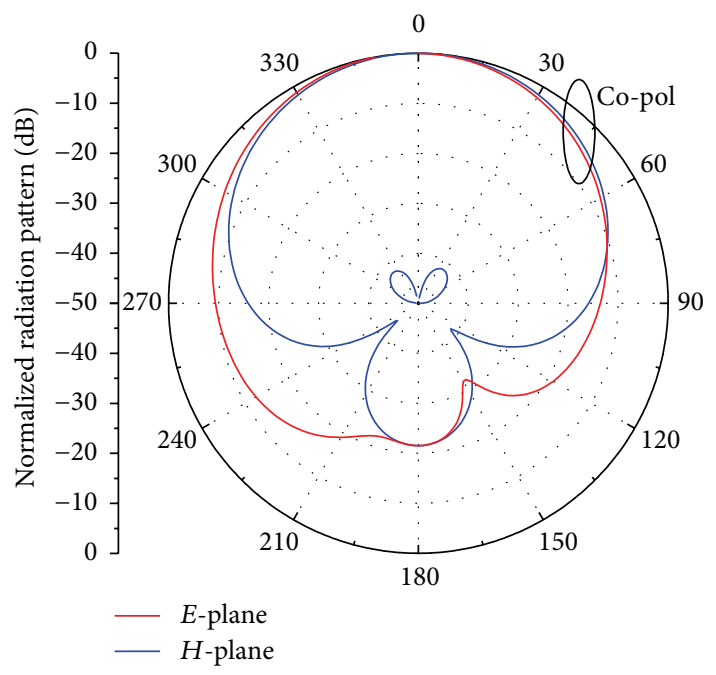

Figure 8: Radiation patterns of the CBHM antenna.

As seen, both radiators have similar overall characteristics. As noted in the PD analysis (Figure 5(b)), the deep valley along the $x y$ plane of the hybrid antenna 3D cross-pol pattern (Figure 9(b)) causes the low cross-pol radiation in the $\mathrm{H}$ plane, as illustrated in Figure 8.

\section{Cavity-Backed SIW Antenna}

The fabrication of the antenna discussed in the previous section is not a simple task. An effective approach based on SIW technology was devised and implemented with a planar copper-clad microwave laminate and a linear array of metallic pins [44]. This approach enables the design of flush-mounted, high-performance antennas of low cost and low weight [53]. In the present case, the metallic walls surrounding the rectangular patch, as shown in Figure 2, are implemented by a series of $1.3 \mathrm{~mm}$ diameter copper pins, as illustrated in Figure 10, where $\Delta c_{t}(t \in\{y, z\})$ is the pin spacing.

The analysis of SIW antennas follows a step-by-step procedure. First, a radiator, named $A-1$, with a large number of pins, embedded in a $100 \mathrm{~mm}$ square copper-clad FR4 laminate $\left(\varepsilon_{r}=4.2, \delta=0.02\right.$, and $\left.h=6.6 \mathrm{~mm}\right)$, is designed in HFSS to operate at $2.45 \mathrm{GHz}$, based on the dimensions of the cavity-backed antenna discussed in Section 3.

The copper pins are positioned at a constant $3 \mathrm{~mm}$ distance from the slots of dimensions $b \times \Delta a(\Delta a=10 \mathrm{~mm})$. The values of $\Delta c_{t}$, the number of pins, and the antenna dimensions are shown in column $A-1$ of Table 3 . The resulting 
TABLE 4: Comparisons between CBHM and SIW antenna characteristics.

\begin{tabular}{|c|c|c|c|c|c|}
\hline & CBHM & $A-1$ & $A-2$ & $A-3$ & $A-4$ \\
\hline Bandwidth $[\mathrm{MHz}]$ & 110 & 109 & 109 & 107 & 101 \\
\hline Directivity $[\mathrm{dB}]$ & 7.4 & 7.4 & 7.1 & 6.8 & 6.5 \\
\hline Radiation efficiency [\%] & 69.2 & 69.3 & 68.6 & 67.3 & 66.2 \\
\hline CPLH-P $[\mathrm{dB}]$ & -41.6 & -37.5 & -32.5 & -31.6 & -29.2 \\
\hline$\triangle \mathrm{CPLH}-\mathrm{P}[\mathrm{dB}]$ & -43.5 to -39.0 & -39.8 to -34.7 & -34.7 to -29.7 & -33.4 to -28.8 & -31.4 to -26.0 \\
\hline
\end{tabular}

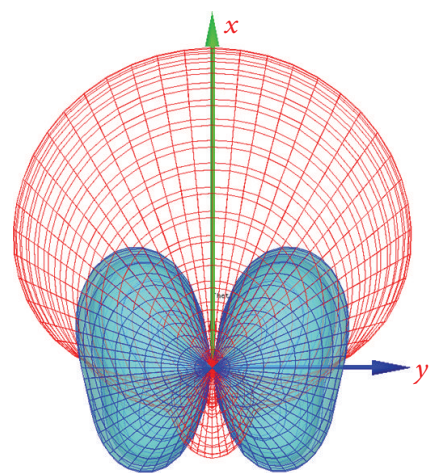

(a)

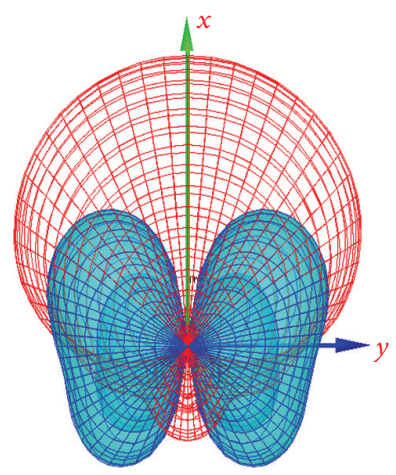

(c)

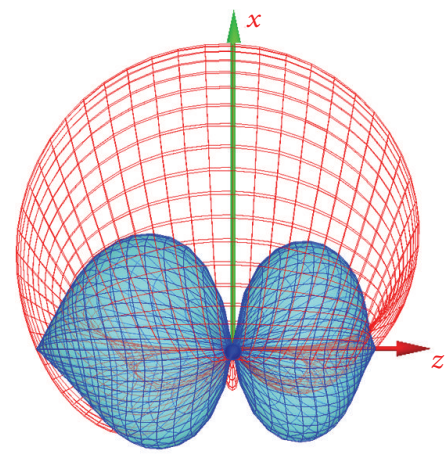

(b)

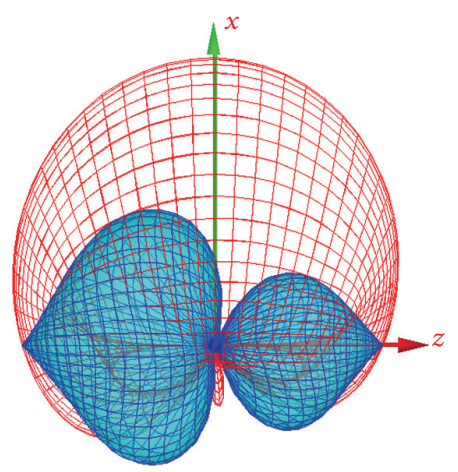

(d)

FiguRE 9: 3D radiation patterns. (a, b) CBHM antenna. (c, d) Conventional probe-fed rectangular-patch microstrip antenna $\left(\varepsilon_{r}=4.2, \delta=\right.$ $0.02, h=6.6 \mathrm{~mm}, a=26.2 \mathrm{~mm}, b=35 \mathrm{~mm}, y_{p}=b / 2$, and $\left.z_{p}=5 \mathrm{~mm}\right)$. Co-pol: red pattern; cross-pol: blue pattern.

curves of input impedance, reflection coefficient magnitude, and CPLH-P are presented in Figures 11 and 12.

Radiation patterns of the co-pol and the cross-pol components, simulated at $2.45 \mathrm{GHz}$ and plotted in the $E$ - and $H$ planes, are shown in Figures 13 and 14.

For comparison, the CBHM antenna curves are superimposed. As seen, the electrical characteristics of antenna $A-1$ are similar to the CBHM radiator, even for the CPLH$\mathrm{P}$ parameter, over the antenna bandwidth. This is because the $6 \mathrm{~mm}$ pin spacing (about 10\% of the wavelength in the FR4 substrate, at $2.45 \mathrm{GHz}$ ) makes up for good metallic walls. Next, by removing some pins from antenna $A-1$, three other radiators, named $A-2, A-3$, and $A-4$, are analyzed. The values of $\Delta c_{t}$, the number of pins, and the antenna dimensions are also listed in Table 3 whereas the simulated results are superimposed in Figures 11-14. Although no significant changes in the input impedance and the reflection coefficient magnitude curves are detected, substantial degradation of the CPLH-P is observed over the ISM band. From the radiation pattern curves (Figures 13 and 14), it is visible that the reduction in the number of pins (with their consequent larger spacing) will degrade the cross-polarization in the $H$-plane, increase the antenna back lobe, and enhance the $E$-plane radiation pattern asymmetry, thus decreasing the antenna directivity.

Additional comparisons are made in Table 4. The antenna directivity, CPLH-P, and radiation efficiency were calculated at the operating frequency. The bandwidth is based, as before, on $|\Gamma| \leq-10 \mathrm{~dB}$, whereas the parameter $\triangle \mathrm{CPLH}$ $\mathrm{P}$ characterizes the variation of CPLH-P over the antenna bandwidth. Since, as previously noted, the overall behavior of the $A-1$ antenna is close to the CBHM radiator, pin spacing $\Delta c_{t} \leq 10 \%$ of the substrate wavelength is taken as the design criterion for SIW antennas. 


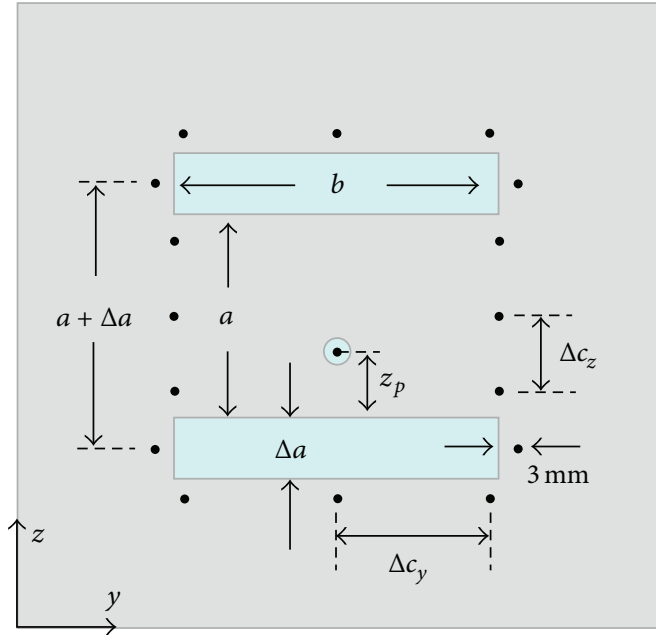

FIGURE 10: Geometry of the proposed SIW antenna.

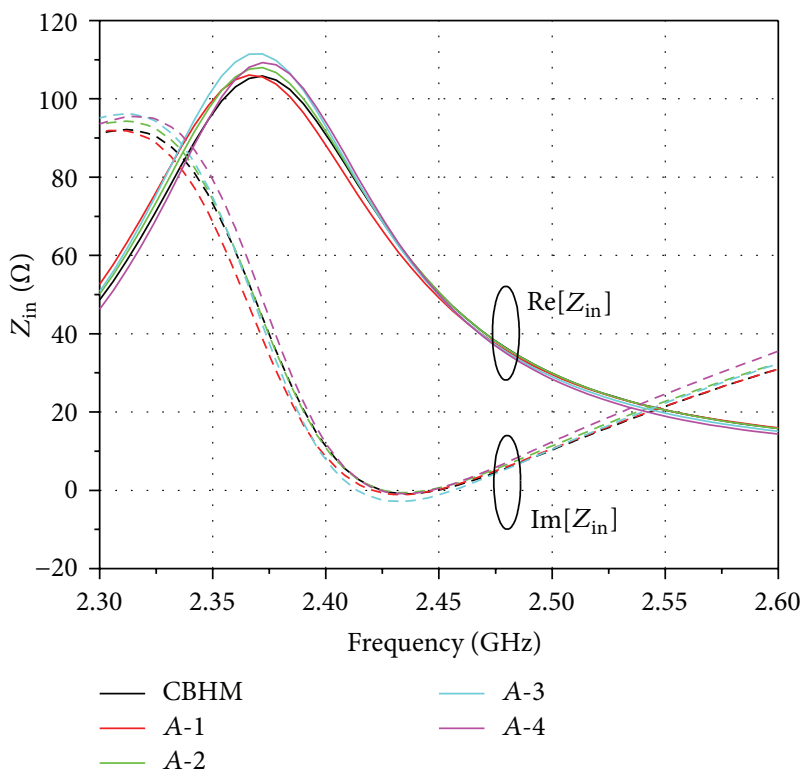

FIGURE 11: Input impedance of the SIW antenna.

\section{Mutual Coupling Analysis}

Mutual coupling is an important effect related to array design. For the specific case of microstrip antennas, mutual coupling, as much as the radiation patterns, is dependent on the thickness and the electrical characteristics of the substrate, the ground plane dimensions, and the separation between the patches and their relative positions. For this paper's purpose, the analysis of mutual coupling follows a step-bystep procedure. First, the radiation patterns of four arrays, one made out of two CBHM patches and the other three of two SIW ones, symmetrically positioned in relation to the center of a $150 \mathrm{~mm} \times 250 \mathrm{~mm}$ rectangular copper-clad FR4 laminate, are simulated in HFSS for fixed $\lambda_{0} / 2$ displacement between the geometric centers of the patches. Two classical arrangements are discussed: the side-by-side configuration,

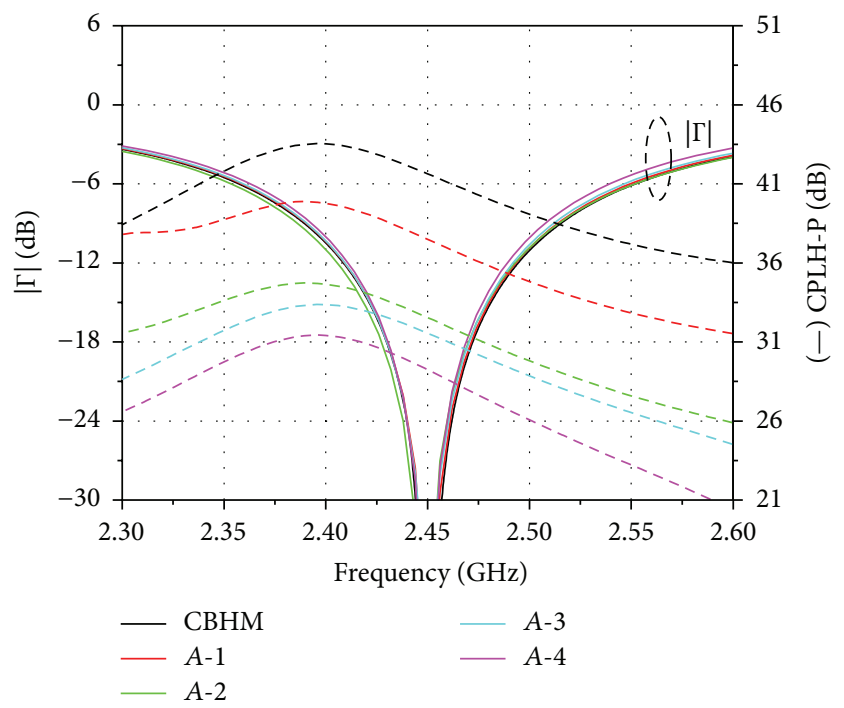

FIGURE 12: Reflection coefficient magnitude and CPLH-P of the SIW antenna.

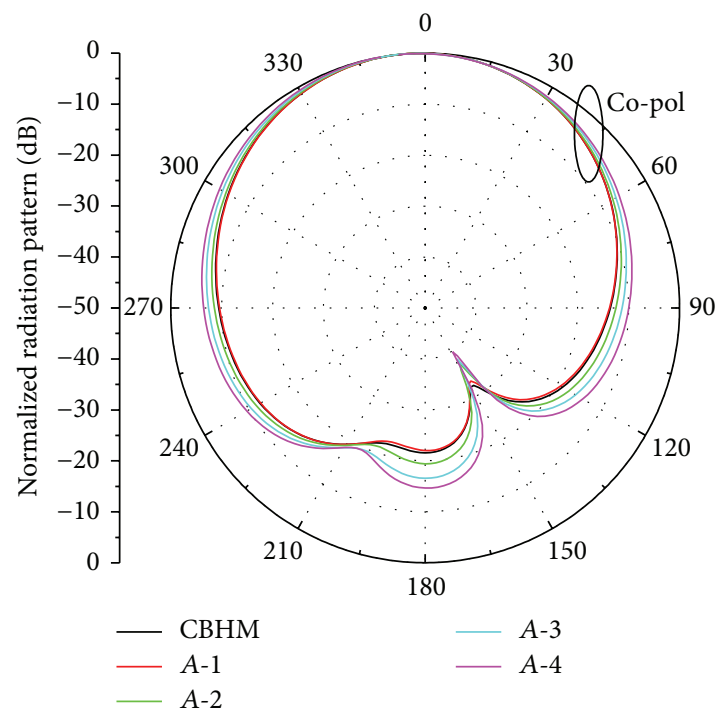

FIGURE 13: E-plane radiation patterns.

as shown in Figure 15, of CBHM antennas, and the collinear one, illustrated in Figure 16. Radiation patterns for these arrays excited at $2.45 \mathrm{GHz}$ in the broadside condition are shown in Figures 17 and 18.

As seen from Figure 17, the $H$-plane radiation patterns of the side-by-side configurations of antennas listed in Table 3 are very similar. In contrast, the collinear SIW configurations exhibit asymmetric $E$-plane radiation patterns (Figure 18), like those in Figures 4(a), 8, and 13. To illustrate this effect, simulations were conducted for arrays excited by only one of the elements (antenna 1), whereas the other radiator (antenna 2 ) is connected to $50-\Omega$ termination. Results for the radiation patterns (at $2.45 \mathrm{GHz}$ ) are shown in Figures 19 and 20.

From the similar radiation patterns that resulted for the side-by-side configurations, one can infer that their near 


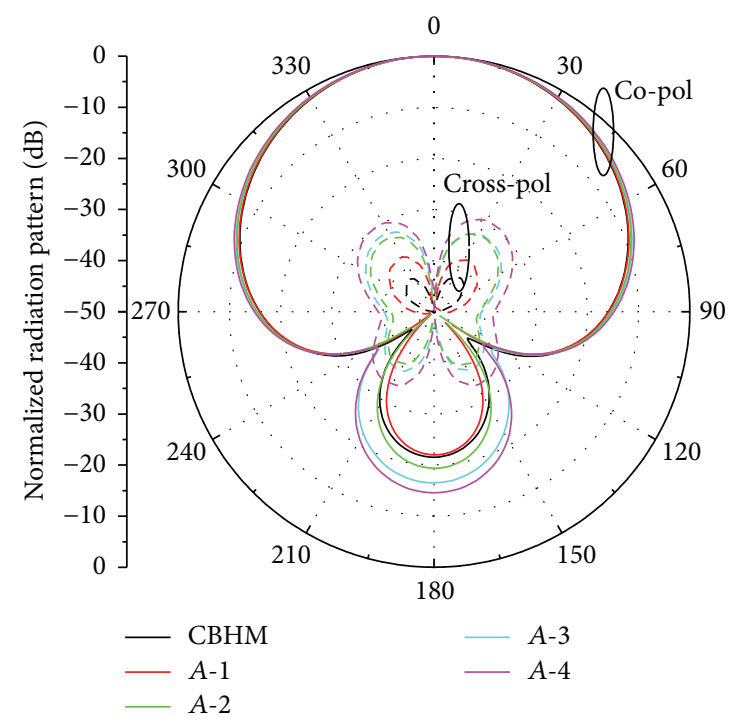

FIGURE 14: $H$-plane radiation patterns.

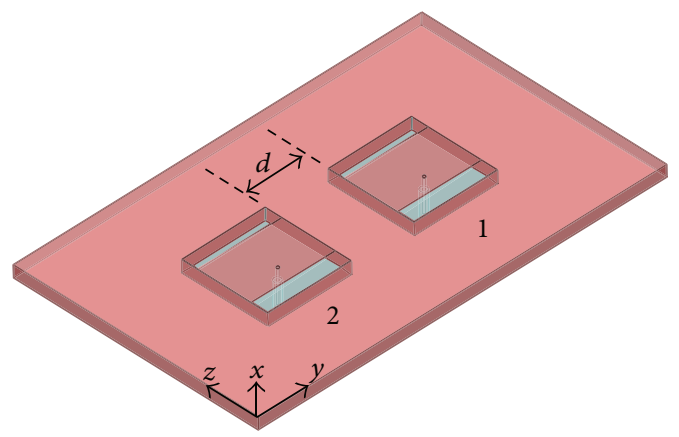

FIGURE 15: Side-by-side array of CBHM antennas.

fields are not too far off. On the contrary, the radiation patterns obtained for the collinear configuration are asymmetric and quite different from one another, since the $E$-plane is strongly affected by the coaxial probe. With the far fields from the collinear arrays being different, it is reasonable to assume that their near fields are so too, thus substantially affecting the mutual coupling between the radiators.

To complete the analysis, the mutual coupling $\left|S_{21}\right|$ as a function of the displacement $d$ between the radiators (as illustrated in Figures 15 and 16) is plotted in Figures 21 and 22. For the side-by-side configuration (Figure 21), the mutual coupling consistently increases as the number of pins decreases, since their near-field structures are close enough.

For the collinear configuration, similar performance is observed for arrays made out of $A-1$ and CBHM patches (Figure 22). This is not however what the curves for $A-2$ and $A-3$ antenna arrays depict. As seen from Figure 22, the mutual coupling level between $A-2$ antennas is below that for the CBHM radiators through $d=18 \mathrm{~mm}$; but beyond that point both $\left|S_{21}\right|$ curves exhibit quite the same behavior. On the other hand, the mutual coupling level between $A-3$ antennas remains below that for $\mathrm{CBHM}$ radiators all over the simulated

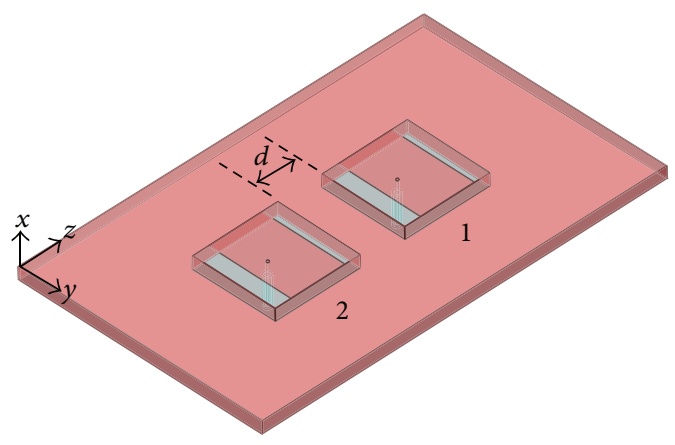

FIgURE 16: Collinear array of CBHM antennas.

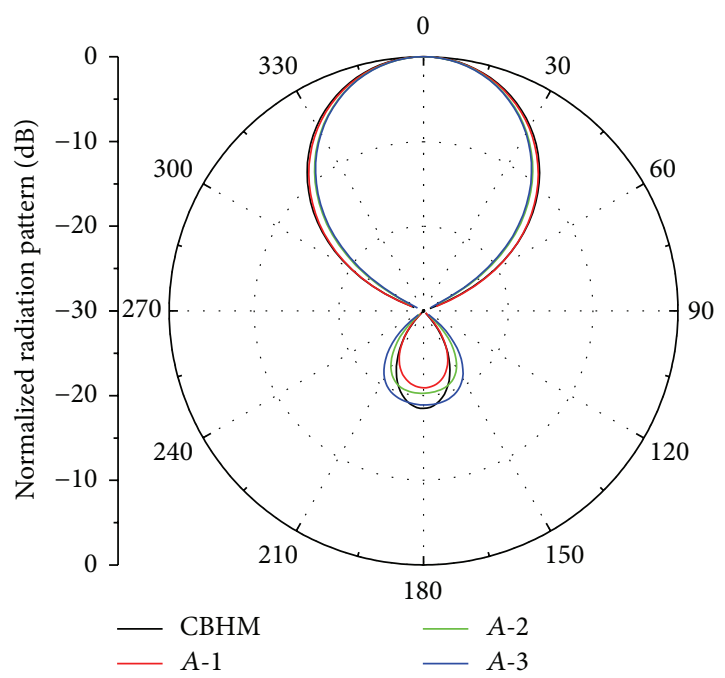

FIGURE 17: $H$-plane radiation patterns: side-by-side configuration.

range. These peculiar behaviors are attributed to the different near-field structures of each radiator type.

\section{Prototype Manufacture and Test}

For this paper's purpose of implementing SIW radiator at $2.45 \mathrm{GHz}$, the $A-1$ antenna is definitely the best choice. However, from a practical point of view, $A-3$ presents a good tradeoff between electrical characteristics and number of pins. Thus, to validate this new antenna topology, the $A-3$ antenna was selected for fabrication. The resulting prototype is pictured in Figure 23 and its experimental reflection coefficient magnitude and input impedance curves are presented in Figure 24.

As noticed, the experimental curves are in very good agreement with the simulated ones. The $8-\mathrm{MHz}$ difference between the measured $(2.442 \mathrm{GHz})$ and the specified operating frequency is attributed to the inaccuracy of the FR4 permittivity value.

In Figure 25, the prototype antenna is seen positioned in the anechoic chamber for the radiation pattern measurement. Experimental and simulated results for the copolarized patterns in both $H$ - and $E$-planes (at $2.45 \mathrm{GHz}$ ), shown in Figures 26 and 27, are in very good agreement. 


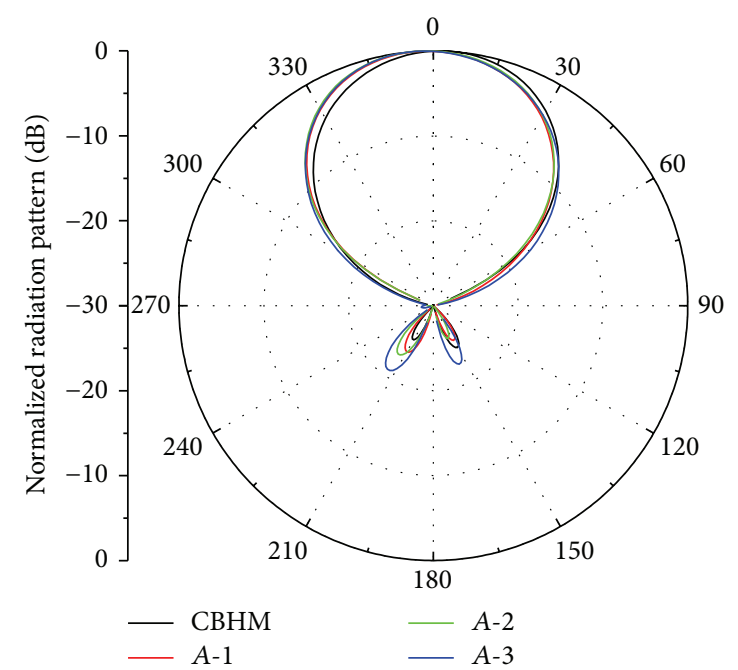

FIGURE 18: E-plane radiation patterns: collinear configuration.

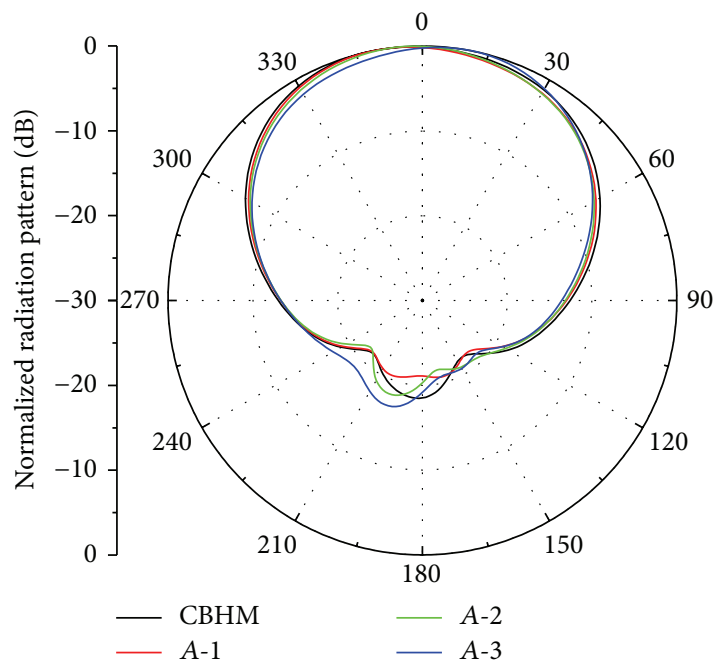

FIGURE 19: $H$-plane radiation patterns: side-by-side configuration.

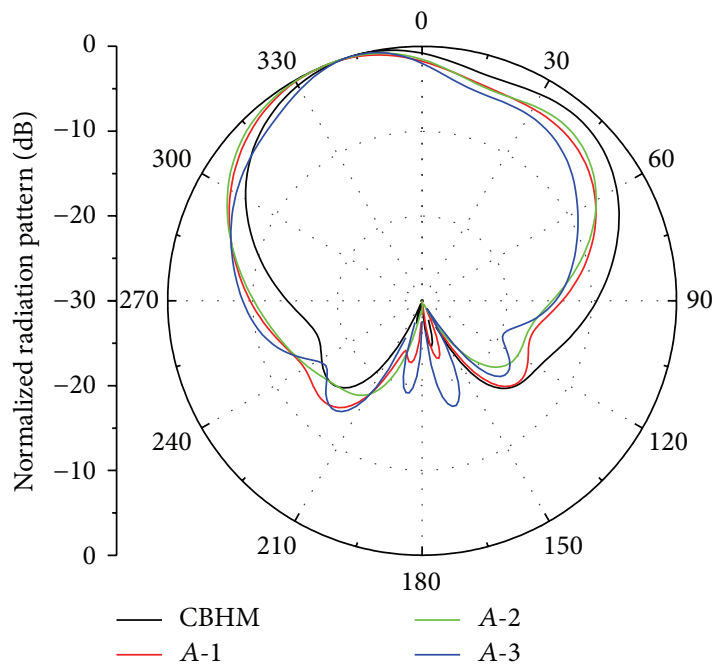

FIGURE 20: E-plane radiation patterns: collinear configuration.

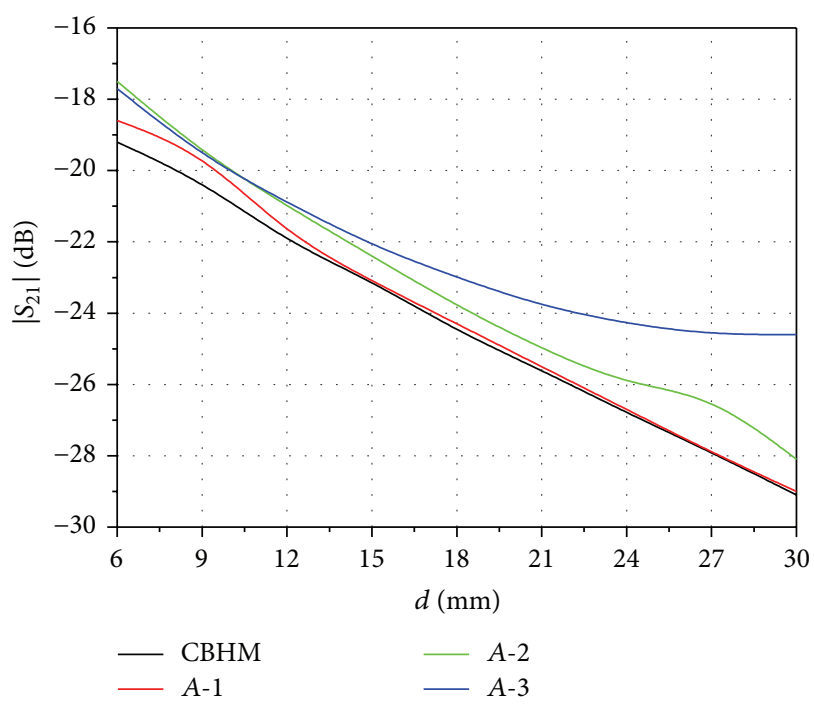

FIGURE 21: Graphics of $\left|S_{21}\right|$ : side-by-side configuration.

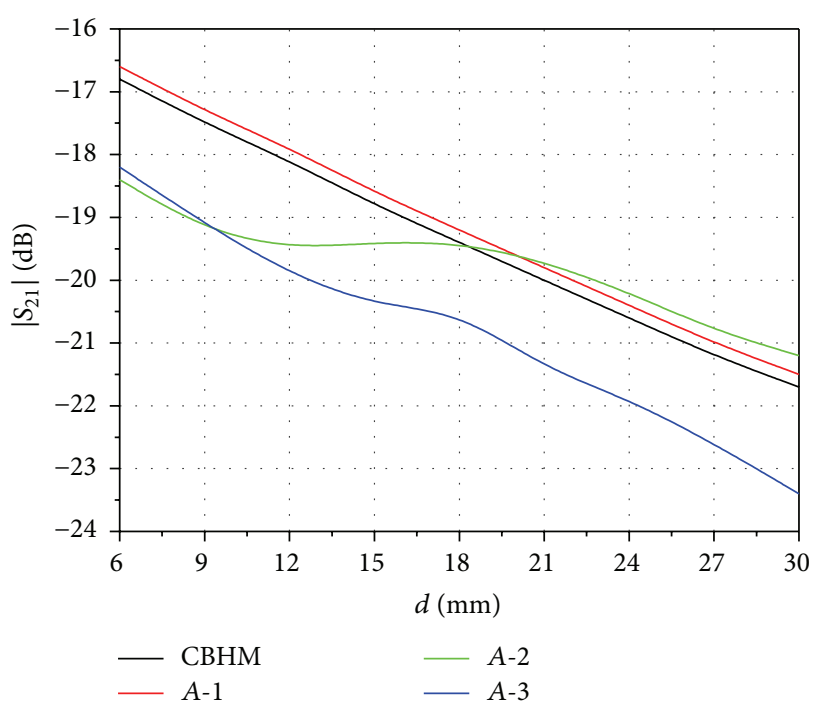

FIGURE 22: Graphics of $\left|S_{21}\right|$ : collinear configuration.

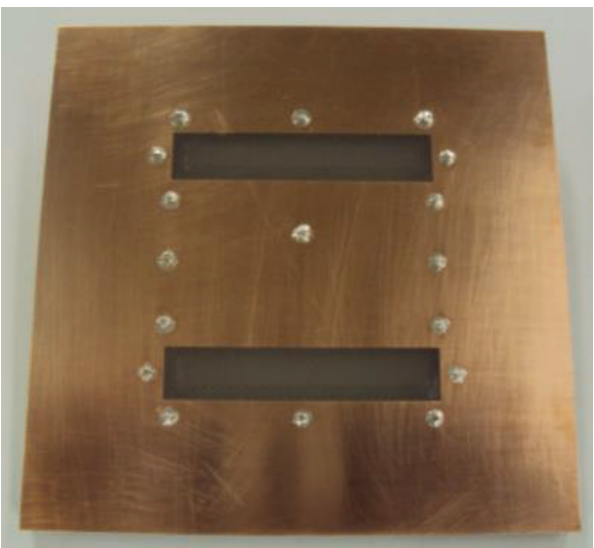

FIGURE 23: A picture of the SIW antenna prototype (based on $A-3$ ). 


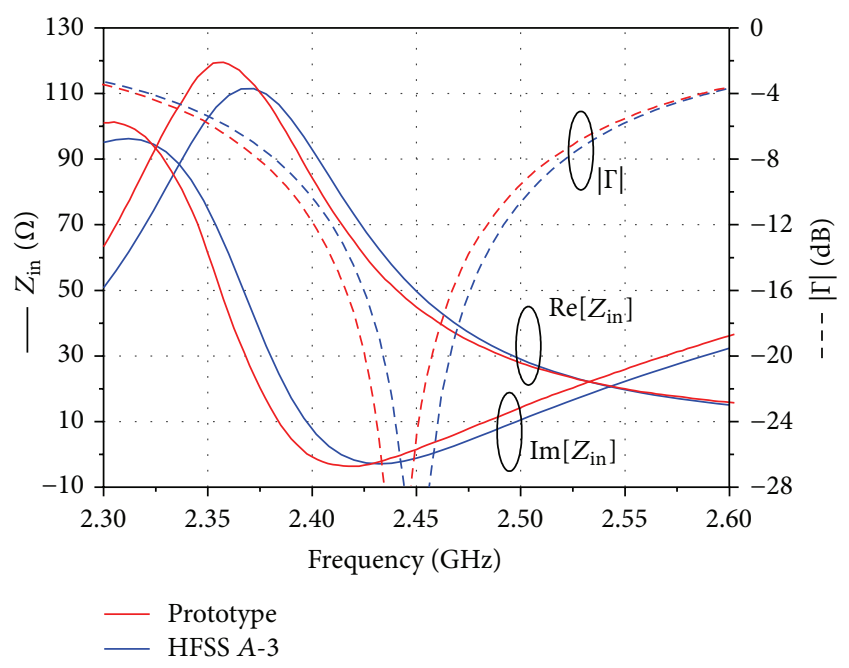

FIGURE 24: Input impedance and reflection coefficient magnitude.

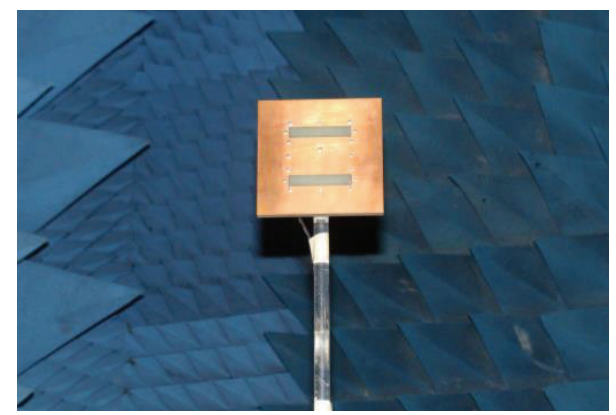

FIGURE 25: SIW antenna in the anechoic chamber.

As to the measured $H$-plane cross-pol, $-26 \mathrm{~dB}$ maximum value occurs on the antenna back side, as shown in Figure 26, thus validating the design procedure.

\section{Final Comments}

A new topology for a low-cost probe-fed linearly polarized microstrip antenna was proposed and implemented. It combines two main concepts: a hybrid patch, for reducing the cross-polarization level in the $H$-plane, backed by a metallic cavity, for suppressing the guided-wave effects. Moreover, the null reactance method was successfully used to compensate for the probe's inductive reactance. Consequently, the new antenna perfectly matches the coaxial feeder and exhibits symmetrical bandwidth. In the present case, a radiator for ISM-band operation was designed on moderately thick FR4 laminate to comply with a requirement for low cost. In order to make the usage of commercial software like the HFSS more effective, the antenna predesign was carried out using the cavity model. However, as this simple model cannot handle the $E$-plane radiation pattern asymmetry, an improvement in the calculation of the far electric field was implemented.

Since the fabrication of the CBHM antenna is not a simple task, SIW technology was adopted. Simulations carried out in HFSS demonstrated its effectiveness whenever the SIW

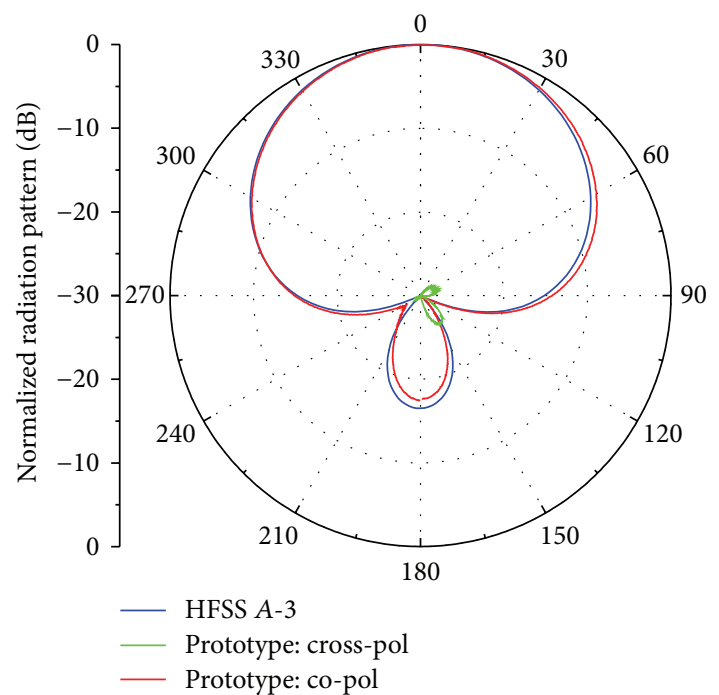

FIGURE 26: $H$-plane radiation patterns.

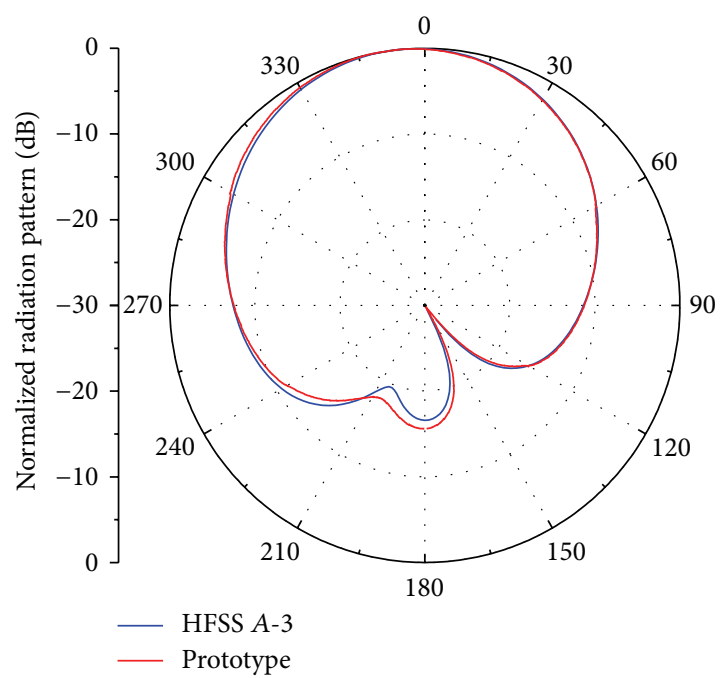

FIGURE 27: E-plane radiation patterns.

antenna design meets the proposed criterion of pin spacing $\leq$ $10 \%$ of the substrate wavelength.

The mutual coupling effects in side-by-side and collinear CBHM and SIW arrays were also analyzed. As expected, similar performance was observed for the arrays made out of $A-1$ and CBHM patches, since the $A-1$ antenna was designed according the aforementioned criterion. On the other hand, the mutual coupling for collinear $A-2$ and $A-3$ antenna arrays has a peculiar behavior, which is attributed to the different near-field structures of these two radiator types.

Finally, a prototype, based on $A-3$ radiator, was implemented and tested. Simulated results for reflection coefficient magnitude, input impedance, and radiation patterns, in very good agreement with experimental ones, validate the proposed geometry.

Although this paper reports a planar antenna manufactured on low-cost material, the same design and construction 
methods apply to antennas on a flexible substrate conformed to cylindrical structures, such as aircraft or a rocket, where low profile is an important requirement.

\section{Conflict of Interests}

The authors declare that there is no conflict of interests regarding the publication of this paper.

\section{Acknowledgments}

The authors would like to thank CNPq for sponsoring Project no. 402017/2013-7, IFI-DCTA for providing the use of the anechoic chamber, and Eng. Nilson Rabelo for the assistance in preparation of the paper.

\section{References}

[1] A. J. Sangster and R. T. Jacobs, "Mutual coupling in conformal microstrip patch antenna arrays," IEE Proceedings: Microwaves, Antennas and Propagation, vol. 150, no. 4, pp. 191-196, 2003.

[2] P. Bhartia, K. V. S. Rao, and R. S. Tomar, Millimeter-Wave Microstrip and Printed Circuit Antennas, Artech House, Norwood, Mass, USA, 1991.

[3] R. Garg, P. Bhartia, I. Bahl, and A. Ittipiboon, Microstrip Antenna Design Handbook, Artech House, Norwood, Mass, USA, 2001.

[4] J. L. Volakis, Ed., Antenna Engineering Handbook, McGraw-Hill, New York, NY, USA, 4th edition, 2007.

[5] R. Gardelli, G. La Cono, and M. Albani, "A low-cost suspended patch antenna for WLAN access points and point-to-point links," IEEE Antennas and Wireless Propagation Letters, vol. 3, no. 1, pp. 90-93, 2004.

[6] R. J. Lelaratne and R. J. Langley, "Dual-band patch antenna for mobile satellite systems," IEE Proceedings: Microwaves, Antennas and Propagation, vol. 147, no. 6, pp. 427-430, 2000.

[7] M. Niroojazi and M. N. Azarmanesh, "Practical design of single feed truncated corner microstrip antenna," in Proceedings of the 2nd Annual Conference on Communication Networks and Services Research, pp. 25-29, New Brunswick, Canada, May 2004.

[8] S.-Y. Ke, "Efficiency improvement of a circularly polarized microstrip antenna using a two-layer substrate," WHAMPOAAn Interdisciplinary Journal, vol. 53, pp. 19-24, 2007.

[9] Y.-F. Lin, H.-M. Chen, and S.-C. Lin, "A new coupling mechanism for circularly polarized annular-ring patch antenna," IEEE Transactions on Antennas and Propagation, vol. 56, no. 1, pp. 1116, 2008.

[10] D. Bhardwa and D. Bhatnagar, "Radiations from double notched square patch antenna on FR4 substrate," Journal of Microwaves, Optoelectronics and Electromagnetic Applications, vol. 7, no. 2, pp. 54-64, 2008.

[11] G. Immadi, M. S. R. S. Tejaswi, M. V. Narayama, N. A. Babu, G. Anupama, and K. V. Raviteja, "Design of coaxial fed microstrip patch antenna for 2.4 GHz BLUETOOTH applications," Journal of Emerging Trends in Computing and Information Sciences, vol. 2, no. 12, pp. 686-690, 2011.

[12] A. A. Qureshi, M. U. Afzal, T. Taqueer, and M. A. Tarar, "Performance analysis of FR-4 substrate for high frequency microstrip antennas," in Proceedings of the China-Japan Joint
Microwave Conference (CJMW '11), pp. 1-4, IEEE, Hangzhou, China, April 2011.

[13] D. C. Nascimento, R. Schildberg, and J. C. S. Lacava, "New considerations in the design of low-cost probe-fed truncated corner microstrip antennas for GPS applications," in Proceedings of the IEEE International Symposium on Antennas and Propagation Society, pp. 749-752, IEEE, Honolulu, Hawaii, USA, June 2007.

[14] M. M. Vazquez, "Low-cost RHCP array at $5.8 \mathrm{GHz}$ for FPV ground stations," in Proceedings of the IEEE Antennas and Propagation Society International Symposium (APSURSI '13), pp. 2227-2228, IEEE, Orlando, Fla, USA, July 2013.

[15] C. Nascimento, R. Schildberg, and J. C. S. Lacava, "Design of low-cost microstrip antennas for Glonass applications," PIERS Online, vol. 4, no. 7, pp. 767-770, 2008.

[16] D. C. Nascimento, R. Schildberg, and J. C. S. Lacava, "Design of probe-fed circularly-polarized rectangular-patch thick microstrip antenna revisited," in Proceedings of the IEEE Antennas and Propagation Society International Symposium (APSURSI '10), pp. 1-4, IEEE, Toronto, Canada, July 2010.

[17] D. C. Nascimento and J. C. S. Lacava, "Design of low-cost probe-fed microstrip antennas," in Microstrip Antennas, N. Nasimuddin, Ed., chapter 1, pp. 1-26, InTech, Rijeka, Croatia, 2011.

[18] A. A. Kishk and L. Shafai, "The effect of various parameters of circular microstrip antennas on their radiation efficiency and the mode excitation," IEEE Transactions on Antennas and Propagation, vol. 34, no. 8, pp. 969-976, 1986.

[19] A. Petosa, A. Ittipiboon, and N. Gagnon, "Suppression of unwanted probe radiation in wide band probe-fed microstrip patches," Electronics Letters, vol. 35, no. 5, pp. 355-357, 1999.

[20] Y. Hu, D. R. Jackson, J. T. Williams, S. A. Long, and V. R. Komanduri, "Characterization of the input impedance of the inset-fed rectangular microstrip antenna," IEEE Transactions on Antennas and Propagation, vol. 56, no. 10, pp. 3314-3318, 2008.

[21] D. M. Pozar, "Considerations for millimeter wave printed antennas," IEEE Transactions on Antennas and Propagation, vol. 31, no. 5, pp. 740-747, 1983.

[22] D. C. Nascimento and J. C. S. Lacava, "Cavity-backed hybrid microstrip antenna on FR4 substrate," in Proceedings of the IEEE Antennas and Propagation Society International Symposium (APSURSI '13), pp. 166-167, Orlando, Fla, USA, July 2013.

[23] P. C. R. Filho, D. C. Nascimento, A. F. Tinoco-S, and J. C. S. Lacava, "Design of flush-mounted hybrid microstrip antennas," in Proceedings of the 15th SBMO/IEEE MTT-S International Microwave and Optoelectronics Conference (IMOC '13), pp. 1-5, IEEE, Rio de Janeiro, Brazil, August 2013.

[24] D. Ghosh, S. K. Ghosh, S. Chattopadhyay et al., "Physical and quantitative analysis of compact rectangular microstrip antenna with shorted non-Radiating edges for reduced cross-polarized radiation using modified cavity model," IEEE Antennas and Propagation Magazine, vol. 56, no. 4, pp. 61-72, 2014.

[25] J. T. Aberle, "On the use of metallized cavities backing microstrip antennas," in Proceedings of the IEEE Antennas and Propagation Society International Symposium, vol. 1, pp. 60-63, IEEE, London, Canada, June 1991.

[26] E. Chang, S. A. Long, and F. R. William, "An experimental investigation of electrically thick rectangular microstrip antennas," IEEE Transactions on Antennas and Propagation, vol. 34, no. 6, pp. 767-772, 1986.

[27] P. S. Hall, "Probe compensation in thick microstrip patches," Electronics Letters, vol. 23, no. 11, pp. 606-607, 1987. 
[28] M. J. Alexander, "Capacitive matching of microstrip antennas," Proceedings of the IEEE, vol. 137, no. 2, part H, pp. 172-174, 1989.

[29] S. Hall, J. S. Dahele, and P. M. Haskins, "Microstrip patch antennas on thick substrates," in Proceedings of the IEEE Antennas and Propagation Society International Symposium (AP-S '89), pp. 458-462, San Jose, Calif, USA, June 1989.

[30] G. A. E. Vandenbosch and A. R. Van de Capelle, "Study of the capacitively fed microstrip antenna element," IEEE Transactions on Antennas and Propagation, vol. 42, no. 12, pp. 1648-1652, 1994.

[31] P. M. Haskins and J. S. Dahele, "Capacitive coupling to patch antenna by means of modified coaxial connectors," Electronics Letters, vol. 34, no. 23, pp. 2187-2188, 1998.

[32] P.-L. Teng, C.-L. Tang, and K.-L. Wong, "A broadband planar patch antenna fed by a short probe feed," in Proceedings of the Asia-Pacific Microwave Conference, pp. 1243-1246, December 2001.

[33] F. A. Chan and K. L. Wong, "A broadband probe-fed patch antenna with a thickened probe pin," in Proceedings of the AsiaPacific Microwave Conference (APMC '01), pp. 1247-1250, IEEE, Taipei, Taiwan, 2001.

[34] Y.-B. Tzeng, C.-W. Su, and C.-H. Lee, "Study of broadband CP patch antenna with its ground plane having an elevated portion," in Proceedings of the Asia-Pacific Microwave Conference (APMC '05), vol. 4, pp. 1-4, December 2005.

[35] D. C. Nascimento, J. A. Mores Jr., R. Schildberg, and J. C. S. Lacava, "Low-cost truncated corner microstrip antenna for GPS application," in Proceedings of the IEEE Antennas and Propagation Society International Symposium (APS '06), pp. 1557-1560, IEEE, Albuquerque, NM, USA, July 2006.

[36] D. C. Nascimento, J. A. Mores Jr., R. Schildberg, J. C. S. Lacava, and L. Cividanes, "Linearly polarized microstrip antennas: new design procedure," Journal of Microwaves, Optoelectronics and Electromagnetic Applications, vol. 6, no. 2, pp. 346-363, 2007 (Portuguese).

[37] D. C. Nascimento, I. Bianchi, R. Schildberg, and J. C. S. Lacava, "Design of probe-fed truncated corner microstrip antennas for Globalstar system," in Proceedings of the IEEE Antennas and Propagation Society International Symposium, pp. 3041-3044, IEEE, Honolulu, Hawaii, USA, June 2007.

[38] L. F. Marzall, D. C. Nascimento, R. Schildberg, and J. C. S. Lacava, "An effective strategy for designing probe-fed linearlypolarized thick microstrip arrays with symmetrical return loss bandwidth," PIERS Online, vol. 6, no. 8, pp. 700-704, 2010.

[39] A. F. Tinoco-S, D. C. Nascimento, R. Schildberg, and J. C. S. Lacava, "Analysis and design of rectangular microstrip antennas for educational purposes," IEEE Antennas and Propagation Magazine, vol. 53, no. 1, pp. 151-155, 2011.

[40] A. F. Tinoco-S, D. C. Nascimento, J. C. S. Lacava, and O. M. C. Pereira-Filho, "Design of cavity-backed circularly-polarized cylindrical microstrip antennas," in Proceedings of the IEEE Antennas and Propagation Society International Symposium (APSURSI '12), pp. 1-2, IEEE, Chicago, Ill, USA, July 2012.

[41] R. F. Designer, "Product overview," http://www.ansys.com/Products/Simulation+Technology/Electronics/RF+\&+Microwave/ ANSYS+DesignerRF.

[42] HFSS, Product overview, http://www.ansys.com/Products/ Simulation+Technology/Electronics/Signal+Integrity/ANSYS+ HFSS.
[43] W. F. Richards, Y. T. Lo, and D. D. Harrison, "An improved theory for microstrip antennas and applications," IEEE Transactions on Antennas and Propagation, vol. 29, no. 1, pp. 38-46, 1981.

[44] M. H. A. Hassan, Design and analysis of substrate-integrated cavity-backed antenna arrays for Ku-band applications [Ph.D. thesis], University of Tennessee, Knoxville, Tenn, USA, 2011.

[45] F. Zavosh and J. T. Aberle, "Improving the performance of microstrip-patch antennas," IEEE Antennas and Propagation Magazine, vol. 38, no. 4, pp. 7-12, 1996.

[46] N. C. Karmakar, "Investigations into a cavity-backed circularpatch antenna," IEEE Transactions on Antennas and Propagation, vol. 50, no. 12, pp. 1706-1715, 2002.

[47] O. M. C. Pereira-Filho, "Flush-mounted cylindrical-rectangular microstrip antennas," IET Microwaves, Antennas and Propagation, vol. 3, no. 1, pp. 1-13, 2009.

[48] O. M. C. Pereira-Filho, T. Ventura, C. Rego, A. F. TinocoS, and J. C. S. Lacava, "Cavity-backed cylindrical wraparound antennas," in Microstrip Antennas, N. Nasimuddin, Ed., chapter 7, pp. 131-154, InTech, Rijeka, Croatia, 2011.

[49] D. C. Nascimento, Microstrip antenna arrays on thick substrates with control of main beam direction, side lobe level, and directivity [Ph.D. thesis], Technological Institute of Aeronautics, São José dos Campos, Brazil, 2013 (Portuguese).

[50] E. Penard and J. P. Daniel, "Open and hybrid microstrip antenna," IEE Proceedings H: Microwaves Optics and Antennas, vol. 131, no. 1, pp. 38-44, 1984.

[51] Mathematica, Champain: Wolfram Research, Product overview, http://www.wolfram.com.

[52] E. O. Hammerstad, "Equations for microstrip circuit design," in Proceedings of the 5th European Microwave Conference, pp. 268272, IEEE, Hamburg, Germany, September 1975.

[53] Y. Dong and T. Itoh, "Miniaturized cavity-backed dualpolarized slot antenna," in Proceedings of the IEEE Antennas and Propagation Society International Symposium (APSURSI '12), Chicago, Ill, USA, July 2012. 

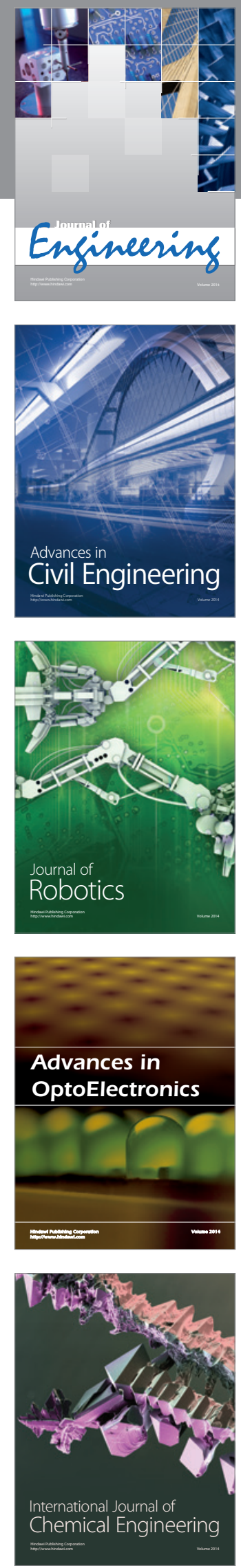

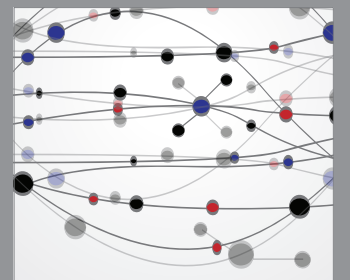

The Scientific World Journal
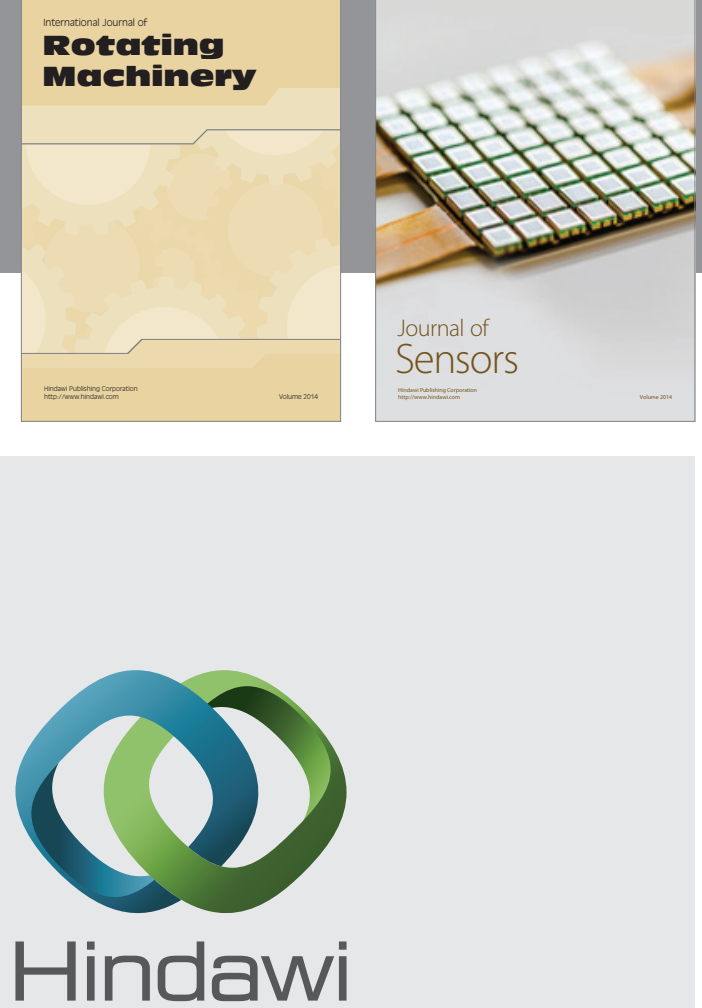

Submit your manuscripts at http://www.hindawi.com
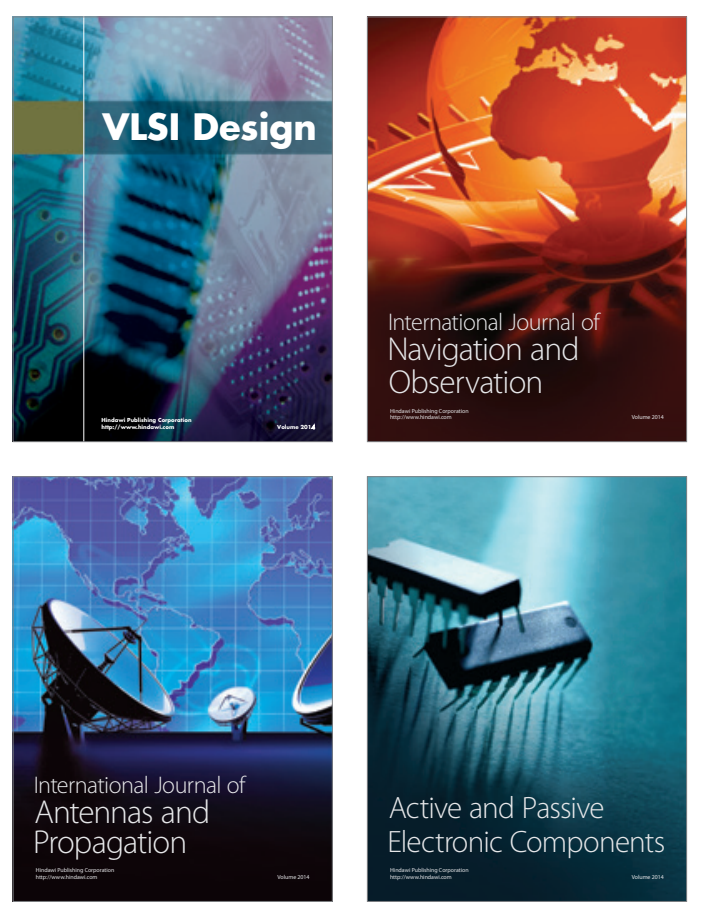
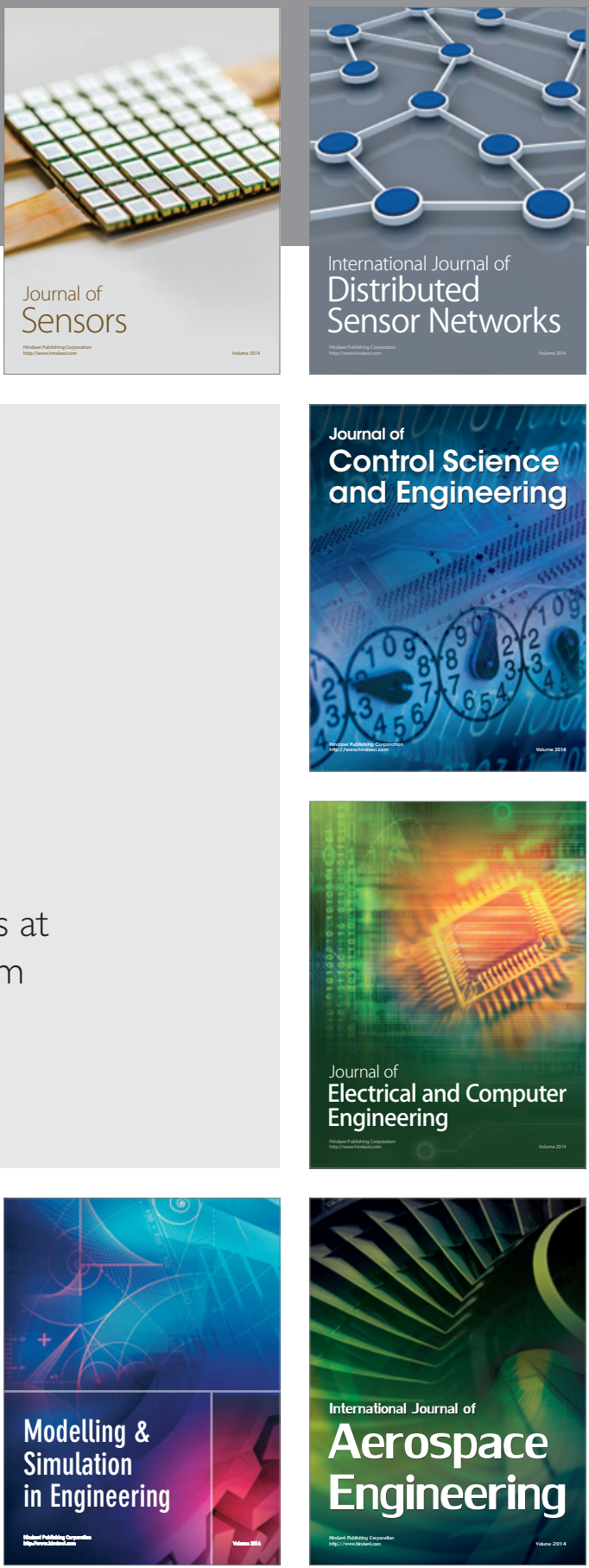

Journal of

Control Science

and Engineering
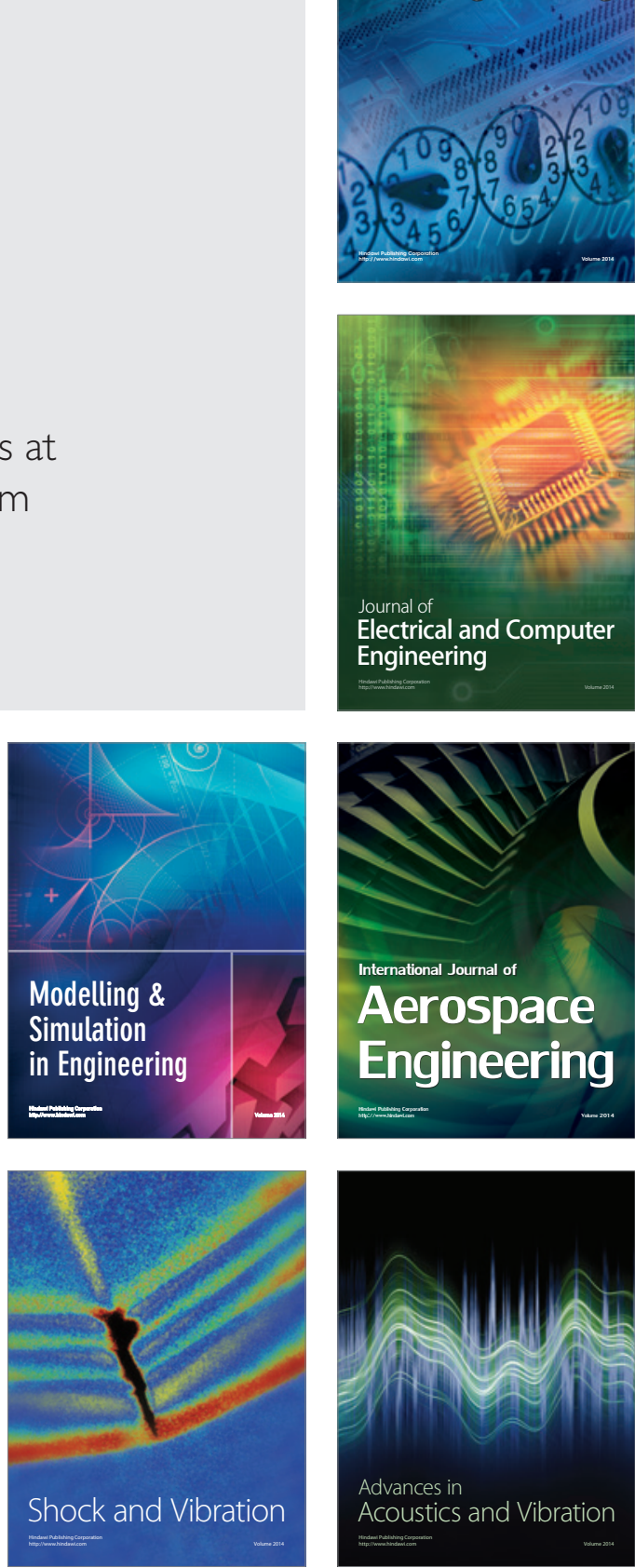